\title{
Nga Vaka o Kaiga Tapu
}

\author{
Rachel Enosa, Fa'amatuainu Tino Pereira, Seini Taufa, Gerardine Clifford-Lidstone, Akesa \\ Filimoehala-Burling, Alliance Community Initiatives Trust, Aotearoa New Zealand
}

\begin{abstract}
Pacific people have lived in Aotearoa New Zealand for over a century. Of Melanesian, Micronesian and Polynesian ancestry, there are over 20 ethnic groups represented under the umbrella term, Pacific, with the largest Pacific groups being of Samoan, Cook Island Māori, Tongan and Niuean ancestry (Taufa, 2015). The growth of these communities in Aotearoa New Zealand has been so rapid that, for some (Cook Island Māori, Niuean and Tokelauans), their communities in Aotearoa New Zealand exceed the size of the populations in their home island influencing their geographic perspective (Hau'ofa, 1994).

Internationally, Aotearoa New Zealand has the highest rate of family violence in the developed world (United Nations Development Fund for Women, 2011) With a population of 4.7 million people, in 2016, family violence accounted for $41 \%$ of a frontline police officer's time with 119,910 family violence investigations made by $\mathrm{New}$ Zealand Police (New Zealand Police, 2017, personal communication).

When broken down by ethnicity, Pacific people are twice as likely to be offenders who have committed a serious crime against a family member; Pacific students are three times as likely as Aotearoa New Zealand European students to report witnessing adults hit children in their homes and five times more likely to die from child abuse or neglect (Pasefika Proud, 2016).
\end{abstract}

Although there is no one single component that can be attributed to family violence, there are three contributing factors that are unique to the experiences of Pacific people in
Aotearoa New Zealand. These are social and economic inequities, the impact of migration on families, and identity and culture. An underlying concern of identity and culture is the urgent need to understand ethnic-specific perceptions, beliefs and practices with regard to relationships between family members, and the impact of violence on kinship wellbeing.

\section{Background}

I have always believed that culture is a vital ingredient for building relationships and meaningful engagement. It is culture that provides us with our unique perspectives, and also culture which often defines the ways we behave, and relate to the world, and shapes our values as collectives of people. (Dame Tariana Turia)

Nga Vaka o Kāiga Tapu was born out of a collaborative process of regional fono run by the New Zealand Ministry of Social Development (MSD) Pacific Advisory Group (PAG) on family violence. The PAG group were made up of clinicians and community leaders who were familiar with the impact of family violence on Pacific communities. The culmination of these events led to a national gathering called the Champions of Change fono, the participants of which collectively identified that culture must be the basis for constructing any solution to family violence.

In 2010, the PAG to the Taskforce for Action on Violence within Families held a fono in four regions throughout the country. The purpose was to seek the views of Pacific people and practitioners on ways to address
AOTEAROA NEW ZEALAND SOCIAL WORK 30(4), 13-18.

CORRESPONDENCE TO: Rachel Enosa rachel.e@acit.org.nz 
family violence in their communities. The culmination of these regional discussions was a national Champions of Change fono held in Auckland where those in attendance identified that any serious approach to addressing violence in Pacific families would require a critical exploration of fundamental issues around culture, its values, practices, traditional contexts, and its ability to encompass the dynamics of contemporary Western society (Ministry of Social Development, 2013).

In March 2011, Cabinet agreed to fund the development and delivery of a Pacific family violence prevention training programme (annual budget of $\$ 1$ million) and a Pasifika Campaign (annual budget of $\$ 500,000$ ).

As expressed in the Cabinet directive, the Pacific family violence prevention training programme is intended to build the capability of Pacific family violence service providers to deliver culturally appropriate interventions. The Pasifika Proud campaign is intended to address the prevention of family violence in Pacific families; designed, delivered and led by Pacific peoples.

Later in 2011, a Practitioners' fono was held where practitioners from different regions met in their ethnic groups to discuss practice imperatives for inclusion in their conceptual frameworks. Discussions also included design and development of the ethnic-specific frameworks. Information for the fono that were held was consolidated to inform the development of the conceptual frameworks. To ensure that the frameworks represented the cultural understandings of each of the Pacific ethnic groups present, each ethnic group had a Working Group and a writer. The writers were selected based on their facilitation skills, bilingual fluency and writing skills.

Supported by the Working Group, the writers were tasked with conducting a literature search and write-up for the conceptual framework for their ethnic group Individuals with relevant expertise from the same ethnic group were then approached to review the ethnic conceptual framework document. After the review and revision of the documents they were submitted to the PAG for their consideration, comment and approval.

Nga Vaka o Kāiga Tapu was officially launched in May 2012 and encapsulates eight ethnic-specific Pacific conceptual frameworks across: Cook Islands, Fiji, Niue, Samoa, Tokelau, Tonga, Kiribati and Tuvalu (see Figure 1). The frameworks set out the key concepts and principles that promote family wellbeing for each of the eight ethnic-specific Pacific communities. The development of the Nga Vaka o Kaiga Tapu Pacific Family Violence Prevention Training Programmes was informed by the frameworks.

At the launch of the frameworks, Dame Tariana Turia noted that "culture is always evolving, and therefore any framework developed for Pacific Nations must also be evolutionary. That is the intention of this document, which brings together not only our cultural perspectives on family violence, but also concepts of wellbeing" (Ministry of Social Development, 2013, p. 3). Consequently, Nga Vaka o Kaiga Tapu has always been a working document.

Following the launch of the frameworks, the family violence prevention training programmes were piloted in the greater Auckland area from 2012-2014. The eight training programmes varied in content, approach to delivery and length. For example, the Samoan programme initially had three modules and 20 sessions, the Tokelauan programme had three modules and three sessions. An evaluation of the process of design and effectiveness of the programmes was undertaken by an independent evaluation service (Malatest) and completed in September 2014.

This article provides an introduction and overview of the Nga Vaka o Kaiga Tapu programme, as a series of publications that will follow the birth and evolution of each of the Pacific ethnic-specific frameworks. 


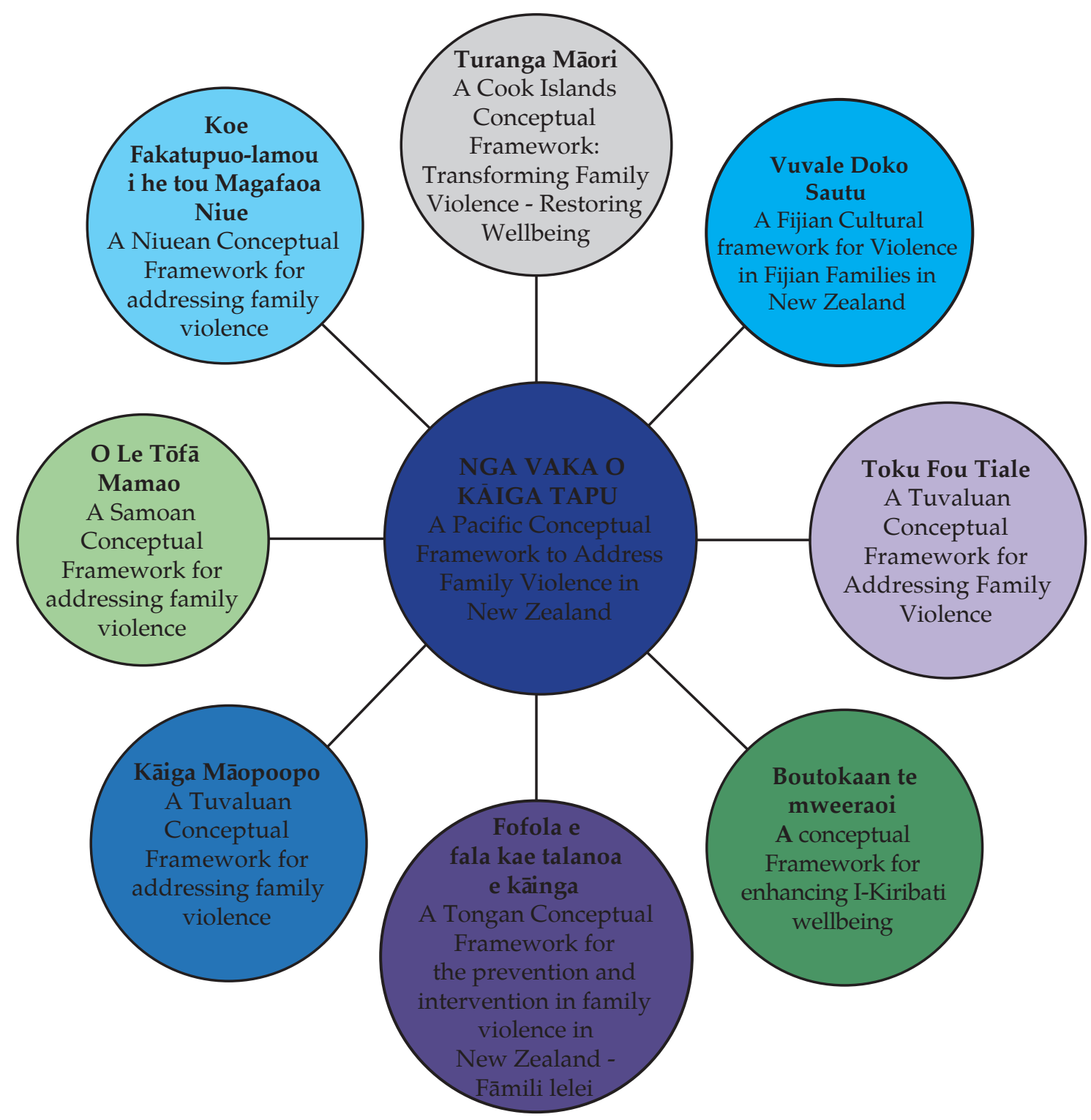

Figure 1. Key documents addressing violence in eight ethnic-specific communities.

\section{Programme objectives}

In 2016, Alliance Community Initiative Trust (ACIT) was contracted to implement the findings from the Malatest evaluation, to operationalise the cultural frameworks and trial a refreshed Samoan and Cook Islands programme. Upon the completion of evaluation by Malatest for the two programmes, findings were incorporated into the development of subsequent programmes. Based on the findings of the independent evaluation, ACITs contract was extended to include the delivery of Pacific Family Violence Prevention Training Programmes (PFVPTP) to the Tongan, Niuean, Fijian, Tuvaluan, Tokelauan and I-Kiribati communities.

Programme objectives for the PFVPTP included:

- Building the capability of Pacific family violence practitioners and 
service providers to provide culturally appropriate interventions for victims, perpetrators and their families.

- $\quad$ Building best practice and training support for practitioners working with Pacific families/communities where there is violence.

ACIT also sought input from key stakeholders who indicated that, in order to achieve the objectives, the following outcomes would assist in successfully meeting programme objectives.

- Community influencers have increased awareness of and confidence to be responsive to issues of family violence within their sphere of influence.

- Practitioners are knowledgeable about and can implement culturally grounded frameworks as a response to addressing family violence.

- A strong network of trained Pacific family violence facilitators nationwide and an established and active community of practice for Pacific family violence practitioners.

- Ongoing opportunities to build the capacity and capability of Pacific family violence facilitators.

- An established pool of Pacific guest speakers who can safely and appropriately represent the diverse views of victims, people who have used violence, experienced practitioners who work in family violence, the Church and community in the context of Nga Vaka o Kaiga Tapu.

\section{Creating an effective Pacific "Train the Trainer" programme}

The importance of high quality and experienced ethnic-specific facilitators is highlighted in the preliminary evaluation findings as fundamental to the success of the programmes. By 2018, all programmes have a lead facilitator and a co-facilitator. Lead facilitators were chosen based on recommendations from their respective Working Group, and had to be skilled in facilitation, be culturally and linguistically competent, have a strong understanding of family violence as it related to Pacific peoples in the Aotearoa New Zealand context, and be competent in both mainstream and their ethnic-specific surroundings.

\section{Programme delivery}

Between 2016 and 2017, all programmes were five days in duration (five modules). The length of the programme was determined by programme content which covered: 1. Introduction to family violence; 2. Dimensions and dynamics of family violence; 3 . Working with diverse (ethnicspecific) families; 4 . Working with (ethnicspecific) family members who use violence; and 5. Working with (ethnic-specific) family members who experience violence. For each module there is an expectation that the cultural framework would govern key learnings.

Within the five-day programme, guest speakers from different agencies (i.e., Brainwaves Trust, Whitireia Community Law, NZ Police) also provided very useful and generic information about the impact of family violence which could be used across all programmes.

One of the barriers to participation has been the length of the programme. Through the evaluations, participants and facilitators alike acknowledged difficulty getting the required time off work to participate in a five-day programme. In order to try and mitigate this problem, ACIT split the modules over a two- to three-week period - providing a range of tangible training opportunities and options is likely to improve uptake and commitment to the programme. 


\section{Participant learning needs}

Learning from the pilot programmes highlight that qualified practitioners who participated in the training found the generic family violence modules (legislation, data, types of abuse, risk management, safely planning) useful but noted that they covered topics that had been addressed comprehensively as part of gaining their formal qualification. These practitioners found the ethnic-specific conceptual frameworks and ways of working with each culture more useful as it is content that they have not previously been taught or exposed to.

On the other hand, participants who are community influencers, volunteers, community support workers and/or from the unregulated workforce found both the generic family violence content and the conceptual frameworks to be highly useful because they had not previously been exposed to any of the information. In addition to this, participants who did not speak their mother tongue or who had limited exposure to their culture as part of their upbringing found the training to be very useful but often felt "lost" when the facilitator or participants started to converse in languages other than English.

This generated a need to diversify the training options in a way that is not complex but meets the diverse needs of learners. This was achieved by separating the generic family violence content from the ethnic-specific conceptual frameworks. This created shorter programmes making it easier for participants to manage their workloads while participating in the programme. A further benefit found was that the information provided in the generic modules is largely pan-Pacific. This meant that any of the lead current lead facilitators can deliver the generic content which increases the pool of available facilitators while broadening the reach of the programme.

\section{Increasing access to the programme}

From 2016-2018, ACIT has held 22 Nga Vaka o Kaiga Tapu trainings nationwide. Feedback from participants about the programme has been overwhelmingly positive and ACIT continues to field numerous enquiries from the community about when the next programmes will be run and how to register for them. A waitlist of potential participants is also currently held by ACIT.

To date, programmes have been run in Dunedin (Cook Island), Christchurch (Samoa), Porirua (Tokelau), Lower Hutt (Fiji), Otahuhu (Niue), Manukau (Samoa, Kiribati, Fijian and Tongan) and Waitakere (Tuvalu). Police apprehension and offending data indicate that areas of particular need are Waitakere, Auckland City, Counties Manukau and Wellington/ Porirua. However, keeping in mind that Pacific peoples are less likely to report family violence incidents to Police, decision making should not be based on Police data alone. Furthermore, ACIT have received enquiries from smaller Pacific communities from the regions who have indicated that, while their numbers are small, improving capability and competence around Pacific family violence is equally as important.

\section{Conclusion}

Nga Vaka o Kāiga Tapu was born out of a collaborative process of regional fono run by the Pacific Advisory Group on family violence. The culmination of these events led to a national gathering called the Champions of Change fono, the participants of which collectively identified that culture must be the basis for constructing any solution to family violence.

Since 2016, ACIT have delivered Pacific Family Violence Prevention Training Programmes with that in mind and, as a result, several success factors have been identified over time, with key insights and solutions also noted (Table 1). 
Table 1. Critical Success Factors, Insights and Solutions

\begin{tabular}{l|l|l|}
\hline \multicolumn{1}{|c|}{ Critical success factor } & \multicolumn{1}{c|}{ Insight } & \multicolumn{1}{c|}{ Solution } \\
\hline $\begin{array}{l}\text { High quality ethnic-specific } \\
\text { facilitators }\end{array}$ & $\begin{array}{l}\text { Competent facilitators who have both } \\
\text { cultural, family violence/social work and } \\
\text { teaching expertise are fundamental to } \\
\text { the success of the programme. }\end{array}$ & $\begin{array}{l}\text { Develop and implement } \\
\text { a comprehensive "train } \\
\text { the trainer" package for } \\
\text { ethnic-specific facilitators. }\end{array}$ \\
\hline $\begin{array}{l}\text { Flexible learner options to meet a } \\
\text { diverse }\end{array}$ & $\begin{array}{l}\text { Evaluation findings affirm the need to } \\
\text { provide a range of customised options } \\
\text { for participants' learning needs }\end{array}$ & $\begin{array}{l}\text { Increase the offerings and } \\
\text { options for participation. } \\
\text { Accommodate for the } \\
\text { needs of Pacific peoples } \\
\text { who are New Zealand }\end{array}$ \\
& $\begin{array}{l}\text { Ability to capture and provide up to } \\
\text { date and relevant metrics is important } \\
\text { for measuring outcomes and impact. }\end{array}$ & $\begin{array}{l}\text { Govt agencies to assist } \\
\text { by providing up-to-date } \\
\text { information and data for } \\
\text { Pacific populations based } \\
\text { on ethnicity, age and } \\
\text { locality. }\end{array}$ \\
& &
\end{tabular}

The Conceptual frameworks have always been viewed as working documents, evolving as culture evolves and through evaluations and constant dialogue with Pacific stakeholders, ACIT continues to work towards improving and refining the programme to cater to and reflect the experiences and needs of our Pacific communities.

\section{References}

Hau'ofa, E. (1994). Our sea of islands. The Contemporary Pacific, 6(1), 148-161.

Ministry of Social Development. (2013). Nga vaka o kaiga tapu: Pasefika Proud family violence research plan
2013-2018. Wellington, NZ: Taskforce for Action on Violence Within Families.

Pasefika Proud. (2016). Pacific peoples in New Zealand Understanding family violence. Retrieved from www. pasefikaproud.co.nz/assets/Resources-for-download/ PasefikaProudResource-Understanding-family-violenceinfographic.pdf

Taufa, S. (2015). A mother's hope: Pacific teenage pregnancy in New Zealand (Unpublished doctoral dissertation), The University of Auckland, New Zealand.

United Nations Development Fund for Women. (2011). Progress of the world's women: In pursuit of justice. Retrieved from http://www.unwomen.org/-/ media/headquarters/attachments/sections/library/ publications/2011/progressoftheworldswomen-2011en.pdf?vs=2835 